\title{
HISTÓRIA DE UM DISTANCIAMENTO: A MEMÓRIA DE PIGLIA NOS DIÁRIOS DE RENZI
}

http://dx.doi.org/10.11606/issn.2237-1184.v0i29p52-61

Júlio Pimentel Pinto

Universidade de São Paulo (USP)

\section{RESUMO}

O texto explora o primeiro volume de Los diarios de Emilio Renzi (1957-1967), de Ricardo Piglia, seus mecanismos de construção da memória, sua problematização da figura do autor - também narrador e personagem - e seu exercício crítico.

\section{ABSTRACT}

The text explores the first volume of Ricardo Piglia's Los diarios de Emilio Renzi (1957-1967), its mechanisms of memory construction, its problematization of the figure of the author - also narrator and character - and its critical exercise.

\section{PALAVRAS-CHAVE:}

Ricardo Piglia;

Los diarios de Emilio Renzi; diário; memória e ficção; crítica.

\section{KEYWORDS}

Ricardo Piglia;

Los diarios de Emilio Renzi; journal; memory and fiction; criticism. 


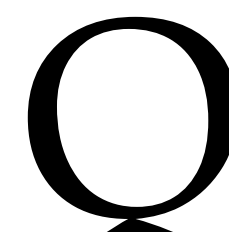

uase no final do primeiro volume de Os diários de Emilio Renzi, o narrador explica:

de todos os signos da linguagem, o Eu é o mais difícil de controlar, o último que a criança adquire e o primeiro que o afásico perde. A meio caminho entre ambos, o escritor adquiriu o hábito de falar de si mesmo como se falasse do outro. ${ }^{1}$

De quem são as memórias lançadas, entre 1957 e 1967, em cadernos esparsos, por um candidato a escritor que então vivia seus "anos de formação" e que quase seis décadas depois - sabendo-se condenado à paralisia e a uma morte triste e provavelmente rápida - as organiza, seleciona, recorta, remonta, reescreve e finalmente publica? Seria - à semelhança do que Gérard Genette escreveu sobre a maioria dos diários um "livro sobre nada"?2 $\mathrm{Na}$ "Nota do autor" do primeiro volume de Os diários de Emilio Renzi, o narrador admite o risco: "No começo as coisas foram difíceis. Ele não tinha nada para contar, sua vida era totalmente trivial."3

Nos três volumes dos diários, os registros funcionam como uma das máquinas narrativas que tanto fascinaram Piglia: eles contam a história alinear da formação de um escritor. Acompanhamos sua infância e os casos que ouviu do avô Emilio - que lutou na Primeira Guerra Mundial por causa de uma paixão. Conhecemos os cursos que fez na Universidade de La Plata, os debates com professores e colegas, as relações familiares e com as mulheres, os amores e a redação de seus primeiros textos. Estrategicamente, no volume 1 e no volume 3, os capítulos alternam o diaa-dia com material ficcional - pequenos contos, esboços de textos -, novamente indeterminando as fronteiras entre realidade e ficção. Não por acaso, o aprendizado do narrador deriva mais do mundo que lê do que do mundo que ele vê:

É com os escritores imaginários que eu aprendo o que quero fazer. Por exemplo, Stephen Dedalus ou Nick Adams. Leio suas vidas como um modo de entender do que se trata. Não tenho interesse em me inspirar nos escritores 'reais'. ${ }^{4}$

\footnotetext{
1 PIGLIA, Ricardo. Os diários de Emilio Renzi. Vol. 1. Anos de formação. São Paulo: Todavia, 2017 (original: 2015; tradução: Sérgio Molina), p. 354.

2 GENETTE, Gérard. Figures IV. Paris: Seuil, 1999, p. 344.

3 PIGLIA, Ricardo. Op. cit., p. 11.

${ }^{4}$ Idem, ibidem, p. 63.
} 
Passear pelas páginas de Os diários de Emilio Renzi permite, ainda, compilar a vertiginosa lista de livros e leituras que movem Renzi/Piglia nesses dez anos: Proust, Lionel Trilling, Melville, De Amicis, Dickens, Verne, Gadda, Sarmiento, Flaubert, Gombrowicz, Virginia Woolf, Kipling, Güiraldes, Chesterton, Sartre, Andréiev, Faulkner, Camus, Onetti, Salinger, Gógol, Heidegger, Bioy Casares, Scott Fitzgerald, Kafka, Bellow, Dostoievski, Walsh, Henry James, Roa Bastos. A lista é imensa e incrivelmente variada. Como o leitor habitual de Piglia pode imaginar, Joyce, Pavese, Arlt, Hemingway e Borges têm lugar privilegiado. É borgeana, aliás, a insistência do narrador em ressaltar o primado da leitura sobre a escrita. Logo no início do primeiro volume, ao comentar sua relação com os livros que leu, atesta:

Como li alguns dos meus livros poderia ser o título de minha autobiografia (caso a escrevesse). Primeiro ponto, portanto, os livros da minha vida mas nem todos os que li, e sim aqueles dos quais lembro com nitidez a situação e o momento em que os lia. Se eu me lembro das circunstâncias em que estava com um livro, isso para mim é a prova de que ele foi decisivo. ${ }^{5}$

Autobiografia fragmentada, descrita como colagem de leituras feitas; passado cifrado nas lembranças dos momentos vividos com livros cujo significado literário pode ser irrelevante, pois eles valem pela persistência na memória, pela capacidade que tiveram de iluminar uma cena vivida, pelas "emoções associadas ao ato de ler. E muitas vezes atribuo a esses livros a paixão da época (que já esqueci)."6 O autor como leitor: o Piglia - jovem espelhado e concentrado em livros esparsos e desordenados pelo tempo - e o olhar ordenador do Piglia-maduro lançado ao passado:

Não são necessariamente os melhores, nem os que me influenciaram: são os que deixaram uma marca. Vou seguir esse critério mnemônico, como se eu contasse somente com essas imagens para reconstruir minha experiência. Um livro na lembrança tem uma qualidade íntima somente se vejo a mim mesmo lendo. Estou do lado de fora, distanciado, e me vejo como se fosse outra pessoa (sempre mais jovem). ${ }^{7}$

"Do lado de fora, distanciado": na capa do livro, quem assina é Ricardo Piglia, mas os diários não são do eu, são do outro: Emilio Renzi. Nem o

\footnotetext{
${ }^{5} I d .$, ib., p. 17.

${ }^{6} I d ., i b .$, p. 19.

${ }^{7} I d .$, ib., pp. $17-8$.
} 
mais incauto leitor que abra as páginas dos três volumes em que Piglia resumiu seus cadernos pode, portanto, se sentir enganado: a sobreposição de telas sobre o passado é explicitada desde o título: Os diários de Emilio Renzi.

Mas quem é Emilio Renzi? Para o leitor, Renzi é um personagem recorrente de Piglia. Ele aparece em sua obra desde a década de 1960, assina textos de crítica, protagoniza contos e atua nos cinco romances que Piglia escreveu, desde Respiração artificial (1980) até O caminho de Ida (2013). Muitos críticos preferem descrever Renzi como alter ego de Piglia: seu segundo eu, seu outro lado, sua projeção e sombra no texto. A associação Piglia/Renzi soa ainda mais perfeita se lembrarmos que o nome completo do escritor é Ricardo Emilio Piglia Renzi - ou seja, Renzi está em Piglia, faz parte de Piglia.

A relação entre os dois, porém, é mais complexa, como já mostram as primeiras linhas de Anos de formação. No texto intitulado "Nota do autor" - logo, supostamente indicativo da pessoalidade do relato - o narrador alerta para a duplicidade Piglia/Renzi ao usar a terceira pessoa para se referir ao autor do diário e ao empregar aspas, recurso de citação, para lhe dar voz:

Tinha começado a escrever um diário no final de 1957 e ainda continuava a escrevê-lo. Muitas coisas mudaram desde então, mas ele permanecia fiel a essa mania. 'Claro que não há nada mais ridículo do que a pretensão de registrar a própria vida. Você imediatamente vira um clown', afirmava. Mesmo assim, ele está convencido de que, se uma tarde não tivesse começado a escrevê-lo, nunca teria escrito mais nada. ${ }^{8}$

Ao caracterizar os diários como a origem e a condição da obra futura, Piglia estabelece um vínculo definitivo entre a suposta verdade contida no diário e o registro imaginativo da ficção; ele cria um "intervalo" e nele combina descompasso e encontro. ${ }^{9}$ É nesse intervalo que se imiscui a imaginação; é esse é o caminho de Piglia na organização de seus cadernos. Nas páginas dos três volumes dos diários, expõem-se as estratégias de especulação e de burla, e a proliferação de sentidos e vozes deslocadas e distanciadas: da leitura dos cadernos à escolha (ou descarte) dos fragmentos, da reescritura às sucessivas revisões, da mão que os escreveu por anos e anos à intermediação da assistente que acompanhou Piglia, bastante doente, nos últimos anos. Assim, a agilidade e a instantaneidade do registro diário foram trocadas pelo ritmo necessariamente lento da construção de um livro e, sobretudo de significados para a experiência

\footnotetext{
8 Id., ib., p. 11.

9 BARBOSA, João Alexandre. A leitura do intervalo. São Paulo: Iluminuras, 1990, p. 15.
} 
perdida. Também a ordem cronológica das anotações de cinquenta e tantos anos sucumbiu ao trabalho seletivo:

Transcrevo meu diário sem seguir uma ordem cronológica, isso seria terrível e muito tedioso, disse. Viajo no tempo, pego os cadernos ao acaso e às vezes estou lendo minha vida em $1964 \mathrm{e}$ de repente já estou no ano 2000 [...] meus cadernos são minha máquina do tempo. ${ }^{10}$

O diário, gradualmente transposto para a forma de livro, reitera a resposta à sua pergunta inicial sobre o motivo de escrever um diário: Piglia não pretendia procurar a realidade; queria recriá-la ou negá-la, como admite ao falar de seus dezesseis anos e dos dias difíceis em que iniciou seus cadernos - logo depois do golpe que derrubou Perón em 1955, seu pai passou quase um ano preso e, uma vez libertado em 57, a família tinha que se mudar de Adrogué e buscar abrigo mais seguro:

Nesses dias, em meio à debandada, num dos cômodos desmantelados da casa, comecei a escrever um diário. O que eu procurava? Negar a realidade, recusar o que estava por vir. Ainda hoje continuo escrevendo esse diário. ${ }^{11}$

Na fronteira volátil entre a história e a ficção, a memória aproveita a brecha que os cadernos oferecem para perscrutar e reencenar o passado, para analisá-lo, interpretá-lo, restaurá-lo seletivamente ${ }^{12}$ e recriá-lo na narrativa; é nela que Piglia estetiza o real e conecta a escrita do diário ao registro do romance, combinando memória, realidade e ficção. A operação é semelhante à de falar de si como se fosse de outro - olhar para si a partir de fora ("gostaria de escrever sobre mim mesmo em terceira pessoa"13), posicionar-se "a meio caminho" entre o eu e o outro, enfatizando mais uma vez a decisão de externalizar a autoria de um relato que a princípio parece tão pessoal, verídico e intransferível, como um diário. Mesmo sem endossar plenamente a "negação autobiográfica", sem "desejar ser um outro"14 e nele concentrar a figura e a possibilidade da autoria, a estratégia deslocadora de Piglia é clara e, ao revelá-la, ele responde ao que Georges Didi-Huberman considera um desafio central na composição de diários:

É terrivelmente difícil apresentar claramente a que estamos nós mesmos direta e vitalmente expostos. Como escrever o que

\footnotetext{
${ }^{10}$ PIGLIA, Ricardo. Op. cit., pp. 373-6.

${ }^{11}$ Idem, ibidem, p. 29.

12 WILLIAMS, Raymond. Marxismo y literatura. Barcelona, Península, 1980 (tradução para o espanhol: Pablo di Masso; original: 1977).

${ }_{13}$ PIGLIA, Ricardo. Op. cit., p. 240.

${ }^{14}$ COUTURIER, Maurice. La figure de l'auteur. Paris: Seuil, 1995, p. 197.
} 
sofremos, como construir um lógos - ou se fazer uma categoria de espécie, uma ideia, um eidos - com seu próprio páthos do momento? ${ }^{15}$

O lógos pigliano é construído pela estratégia de deslocamento e distanciamento desenvolvida em Os diários de Emilio Renzi, traduzida nos gestos de circular livremente pela cronologia, olhar para si como se estivesse fora, combinar o eu ao outro e jamais discerni-los na - como diz, a bonita epígrafe proustiana que abre Anos de formação - "multiplicação de si mesmo, que é a felicidade". Nesse processo cheio de contrastes, o que eram documentos íntimos e pessoais metamorfoseiam-se em material literário a ser publicado - tornado público; o que se supunha desmistificador era um lance a mais na construção de uma obra e de uma persona literária.

Em suma, a assinatura de Renzi no lugar da de Piglia ajuda a afastar qualquer compromisso com a verdade, reivindica o espaço da ficção e desvela o estatuto literário do texto. Da mesma forma, esse distanciamento da autoria e de toda responsabilidade sobre a memória e a evocação do passado orienta o esforço de transpor para o presente a experiência vivida no passado, transmutando-a. Para Didi-Huberman, trata-se de uma "tomada de posição" e ele enfatiza que

é preciso compreender que não há nada de simples em tal gesto. [...] distanciar supõe [...] aguçar seu olhar. [...] Distanciar seria mostrar mostrando que se mostra, e assim dissociando - para melhor demonstrar a natureza complexa e dialética do que se mostra. Nesse sentido, distanciar é mostrar, isto é, desunir as evidencias para melhor unir, visual e temporalmente, as diferenças. [...] Distanciar é saber manipular seu material visual ou narrativo como uma montagem de citações referidas à história real. ${ }^{16}$

O leitor que acompanha a construção dessa memória enviesada não enxerga o passado, mas o diálogo entre os diversos estratos do tempo ${ }^{17} \mathrm{e} o$ recurso à ficção como forma de produzir significados para a experiência histórica e de possuir o passado - e a consciência dele - a partir de fragmentos sutis. ${ }^{18}$ Jacques Rancière, em $O$ fio perdido, analisa o papel revelador que a ficção pode exercer para a apreensão, necessariamente ambígua - e por isso fértil - do real:

\footnotetext{
${ }^{15}$ DIDI-HUBERMAN, Georges. O olho da história. Vol. I. Quando as imagens tomam posição. Belo Horizonte: Editora da UFMG, 2017 (original: 2009; tradução: Cleonice P. Barreto Mourão), p. 27. ${ }^{16}$ Idem, ibidem, pp. 61-3.

${ }^{17}$ KOSELLECK, Reinhart. Estratos do tempo: estudos sobre história. Rio de Janeiro: Contraponto, 2014 (original: 2003; tradução: Markus Hediger).

${ }^{18}$ LOWENTHAL, David. Possessed by the Past. The Heritage Crusade and the Spoils of History. New York: Free Press, 1996.
} 
a ficção não é [apenas] uma invenção de mundos imaginários. Ela é, em primeiro lugar, uma estrutura de racionalidade: um modo de apresentação que torna as coisas, as situações ou os acontecimentos perceptíveis e inteligíveis; um modo de ligação que constrói formas de coexistência, de sucessão e de encadeamento causal entre os acontecimentos e confere a essas formas as características do possível, do real ou do necessário. [...] E os desregramentos da ordem ficcional permitem, contrariamente, pensar as relações entre as palavras e as coisas, as percepções e os atos, as repetições do passado e as projeções no futuro, o sentido do real e do possível, do necessário e do verossímil do qual se tecem as formas da experiência social e da subjetivação política. ${ }^{19}$

Regrar e desregrar, nos termos enunciados por Rancière, são os movimentos a que Piglia recorre - por meio da oscilação na autoria ou do trabalho da memória - para afastar-se da experiência e lhe atribuir significados, para restaurá-la, não mais como realidade, e sim como ficção. No segundo volume dos diários - Os anos felizes -, Piglia esclarece a opção pela narrativa imaginativa:

Nunca me preocupou a ideia de que a literatura nos afastasse da experiência, porque, para mim, as coisas acontecem ao revés: a literatura constrói a experiência. ${ }^{20}$

O comentário, anotado num domingo, 29 de setembro de 1968, antecipa em mais de dez anos a escolha da epígrafe de seu romance mais intenso e mais colado ao momento vivido: Respiração artificial. ${ }^{21}$ Escrito durante a escabrosa ditadura militar argentina, Respiração enfatiza a necessidade de construir o passado para compreender o presente, teoriza sobre as contingências e as possibilidades da história e tenta alcançar, por meio de uma viagem à ficção, alguma compreensão do presente. Sua epígrafe, que pressagia as vertiginosas aventuras de Emilio Renzi e de Marcelo Maggi, é composta por dois versos do célebre “The Dry Salvages”, de T.S. Eliot:

Vivemos a experiência mas perdemos o significado,

E a proximidade do significado restaura a experiência

\footnotetext{
${ }^{19}$ RANCIÈRE, Jacques. O fio perdido: ensaios sobre a ficção moderna. São Paulo: Martins Fontes, 2017 (original: 2013; tradução: Marcelo Mori), p. 11-4.

${ }^{20}$ PIGLIA, Ricardo. Los diarios de Emilio Renzi. Vol. 2. Los años felices. Barcelona: Anagrama, 2016, p. 69. Tradução minha.

${ }^{21}$ PIGLIA, Ricardo. Respiração artificial. São Paulo: Iluminuras, 1987 (original: 1980; tradução: Heloisa Jahn), p. 8.
} 
Vale a pena buscar o poema e prosseguir a leitura por mais alguns versos:

Vivemos a experiência mas perdemos o significado,

E a proximidade do significado restaura a experiência

Sob forma diversa, além de qualquer significado. Como já se disse,

A experiência vivida e revivida no significado

Não é experiência de uma vida apenas

Mas a de muitas gerações - não esquecendo

Algo que, provavelmente, será de todo inefável:

O olhar para além da certeza

Da História documentada, a olhadela,

Por cima dos ombros, lançada ao terror primitivo. ${ }^{22}$

Nenhuma verdade sobre o passado é acessível, pois o significado de toda experiência vivida é volátil e jamais sobrevive aos estratos que se acumulam do tempo, à interferência de novas temporalidades - e "gerações" - , às outras vidas que vivemos posterior ou simultaneamente àquela que pretendemos revisitar. A história, com seus caprichos de dama elegante e seu compromisso com a verdade possível e tangível, documenta poucas e precárias certezas; daí a necessidade de lançar " $a$ olhadela,/ Por cima dos ombros (...) ao terror primitivo" e a todos os terrores que devamos enfrentar. David Lowenthal já observou que a sensação de perda do passado provoca a contínua evocação da experiência vivida e o esforço de de reinventá-la na memória ou na ficção. ${ }^{23}$ Esse anseio de evocar o passado justifica as duas faces e os dois tempos do diário: sua escrita "a quente" e a edição posterior que o reconstrói e restaura, alterados, seus significados. Num tempo ou no outro, o diário é sempre o negativo da realidade. Negase a realidade por meio da mentira - algo próprio da ficção - ; nega-se a realidade para conhecê-la e compreendê-la, para se recriar os significados possíveis da experiência passada, para ordenar o tempo vivido. ${ }^{24}$

Nega-se a realidade para produzir literatura - esta, a preocupação central de Anos de formação. Embora os dois volumes posteriores de Os diários de Emilio Renzi - Os anos felizes, lançado em 2016, e Um dia na vida, de 2017 - também reflitam prioritariamente sobre a literatura, é no livro inicial que ela desponta como objetivo de vida e trabalho do narrador. Piglia/Renzi se prepara para ser escritor, imergir no mundo da ficção e da crítica. A literatura é sua única aposta ("tenho que entender que somente minha literatura interessa (...). Sou alguém que apostou a vida numa única cartada." 25),

\footnotetext{
${ }^{22}$ ELIOT, T.S.. “The Dry Salvages". Quatro quartetos. Obra completa. Volume I. Poesia. São Paulo: Arx, 2004 (original: 1941; tradução: Ivan Junqueira), p. 364-5.

${ }^{23}$ LOWENTHAL, David. The Past Is a Foreign Country. Cambridge: Cambridge University Press, 1985, p. 259.

${ }^{24}$ Idem, ibidem, p. 191 e p. 227.

${ }^{25}$ PIGLIA, 2017, p. 179.
} 
mas a escrita ainda é um alvo na noite, um caminho enigmático a ser trilhado num mundo que precisa ser criado, em que o Eu e o outro se confundem, ora se expõem, ora persistem secretos:

Na literatura, acho, o fundamental é ter um mundo próprio. No meu caso, esse material é secretamente autobiográfico e depende da infinidade de histórias familiares que fui escutando ao longo da vida. ${ }^{26}$

A anotação de janeiro de 1964 é seguida por observação sobre as hesitações da memória e a sobreposição de temporalidades:

Por alguns momentos estou em outro tempo, não se trata de uma lembrança, e sim, antes, de voltar a viver as emoções do passado. [...] Enfim, queria estabelecer uma distinção entre recordar e viver - ou ver-se viver - no passado. ${ }^{27}$

O desassossego do narrador não se restringe à esfera pessoal; ele inclui a constatação acerca do lugar da literatura num período de fortes tensões políticas dentro e fora da Argentina, como quando afirma - talvez antecipando a noção de "ficção paranoica" a que se dedicou tantos anos depois - que "a literatura seria uma alternativa às manipulações da linguagem e aos usos da ficção por parte do Estado"28 ou na interpretação que ensaia a partir da leitura de Dashiell Hammett:

por que se narra dessa maneira? Porque nesse mundo tudo está em perigo, todos se sentem vigiados e a violência pode explodir a qualquer momento. O procedimento narrativo dá a entender tudo isso sem dizê-lo. ${ }^{29}$

Nesse "mundo em perigo" a ficção tem também o papel de instigar a imaginação moral - noção que surgiu com Edmund Burke, no final do século XVIII, e que remete à capacidade de conceber e representar a diversidade do humano e de reconhecer suas peculiaridades e ambiguidades. Nos diários de Piglia, ela assume a condição de imaginação acerca das contingências, ironias, ambiguidades e ambivalências dos textos e dos sujeitos com quem, desde o lugar de leitura e da perspectiva imaginativa que assume, partilha a experiência histórica das frementes décadas de 1960 a 1980 na América Latina.

Sabemos que a tradição literária argentina, desde a metade do século XIX - ou mais especificamente a partir do Facundo, de Sarmiento, um dos

\footnotetext{
${ }^{26}$ Idem, ibidem, p. 163.

${ }^{27} I d$., ib., p. 164.

${ }^{28} I d .$, ib., p. 165.

${ }^{29} I d .$, ib., pp. 158-9.
} 
objetos da leitura frequente e da obsessão analítica de Piglia -, indeterminou as fronteiras entre gêneros e o ensaísmo pôde se misturar com a ficção, a história, o jornalismo, a etnologia, o comentário político e o relato pessoal. É nessa confluência de muitos registros, diferentes entre si mas intercambiáveis, que Os diários de Emilio Renzi mesclam história, memória, ficção e exercício da crítica. É nesse terreno que constrói seus duplos: público e privado, instantaneidade e longa duração, memória e história, leitor e escritor, passado e presente, verdade e ficção, Piglia e Renzi.

Mais de uma vez Piglia referiu-se aos diários como "o romance de uma vida": uma reflexão sobre a figura do autor, fazendo-a vagar entre as condições de narrador e personagem; um gradual desvelamento das leituras e das experiências vividas; uma autobiografia produzida no cotidiano, e décadas depois reinventada ficcionalmente; um olhar de estranhamento e vertigem sobre o passado; uma radiografia dos mecanismos de construção da memória, com a recorrente apropriação individualizada da experiência coletiva; um assombro face à importância da imaginação moral, sobretudo em tempos sombrios; a história de um distanciamento e a reafirmação da centralidade da ficção como gesto crítico para lidar com a inquietante prolixidade do real - prolixidade do real que, já disse Borges, é nossa maior angústia; pode nos paralisar; mas permite também que reconheçamos - tal qual constata o hesitante Emilio Renzi do final de Anos de formação - que mesmo nos momentos mais pérfidos sempre haverá alguém, ou algum texto de ficção, para nos sustentar no ar: "Isso que é narrar, disse em seguida, arremessar-se no vazio e acreditar que algum leitor vai segurá-lo no ar." 30

Júlio Pimentel Pinto é professor no Departamento de História da USP. Pesquisa e estuda as relações entre história e ficção. É autor, entre outros, de A pista e a razão: uma história fragmentária da narrativa policial, editado e distribuído em formato digital em 2019 pela e-galaxia. Contato: juliop@uol.com.br

${ }^{30} I d .$, ib., p. 363. 